\title{
Dihydrocodeine/agonists for alcohol dependents
}

\section{Albrecht Ulmer *, Markus Müller and Bernhard Frietsch}

Gemeinschaftspraxis Dres.med. Ulmer, Frietsch, Mueller, Stuttgart, Germany

\section{Edited by:}

Otto Lesch, Medical University of Vienna, Austria

Reviewed by:

Jennifer G. Plebani, University of Pennsylvania School of Medicine, USA

Henriette Walter, University of Vienna, Austria

*Correspondence:

Albrecht Ulmer, Gemeinschaftspraxis Dres.med. Ulmer, Frietsch, Mueller, Schwabstr. 26, D - 70197 Stuttgart, Germany.

e-mail:albrecht.ulmer@gmx.de
Objective: Alcohol addiction too often remains insufficiently treated. It shows the same profile as severe chronic diseases, but no comparable, effective basic treatment has been established up to now. Especially patients with repeated relapses, despite all therapeutic approaches, and patients who are not able to attain an essential abstinence to alcohol, need a basic medication. It seems necessary to acknowledge that parts of them need any agonistic substance, for years, possibly lifelong. For $>14$ years, we have prescribed such substances with own addictive character for these patients. Methods: We present a documented best possible practice, no designed study. Since 1997, we prescribed Dihydrocodeine $(\mathrm{DHC})$ to 102 heavily alcohol addicted patients, later, also Buprenorphine, Clomethiazole ( $>6$ weeks), Baclofen, and in one case Amphetamine, each on individual indication. This paper focuses on the data with DHC, especially. The Clomethiazole-data has been submitted to a German journal. The number of treatments with the other substances is still low. Results: The 102 patients with the DHC treatment had 1367 medically assisted detoxifications and specialized therapies before! The 4 years-retention rate was $26.4 \%$, including $2.8 \%$ successfully terminated treatments. In our 12 -steps scale on clinical impression, we noticed a significant improvement from mean 3.7 to 8.4 after 2 years. The demand for medically assisted detoxifications in the 2 years remaining patients was reduced by $65.5 \%$. Mean GGT improved from $206.6 \mathrm{U} / \mathrm{l}$ at baseline to $66.8 \mathrm{U} / \mathrm{l}$ after 2 years. Experiences with the other substances are similar but different in details. Conclusion: Similar to the Italian studies with GHB and Baclofen, we present a new approach, not only with new substances, but also with a new setting and much more trusting attitude. We observe a huge improvement, reaching an almost optimal, stable, long term status in around 1/4 of the patients already. Many further optimizations are possible.

\section{Keywords: dihydrocodeine, alcohol addiction}

\section{INTRODUCTION}

We have been documenting the long term profile of addiction diseases in charts for $>20$ years. These charts show the severe chronic character of the disease and the limited effect of most active measures against it in a terrifying manner. Nearly all patients have undergone endless attempts to finally reach a stable abstinence, and most of them ruined themselves in the process. The established way of treatment and possible abstinence as the goal seem to be insufficient or wrong.

If a chronic or polyleptic disease like asthma, hypertension, diabetes, rheumatic disease, and migraine is associated with too many or heavy exacerbations, several sufficient basic treatments have been developed. Not so for alcohol dependence! The need is extremely evident, mainly for patients with no working abstinence and repeated relapses despite all therapeutic approaches and for patients who are not able to reach an urgently needed abstinence of alcohol.

Four main problems are most disturbing from alcohol dependence: The somatic harm, the impossibility to control it sufficiently, the psychological alteration and, like in many addiction diseases, the trust destroying underhandedness. If these disturbances are resolved, even a life with the long term need of a type of medication is acceptable. The relevant goal is that these disturbances disappear. Many people and even experts believe that abstinence is a prerequisite for this - a clear confusion of conditions and goal, especially, if abstinence does not work in the long term, as shown in most of our charts.

Basic medication must help to reduce craving, relapses, and the mentioned alcohol related problems. The first hope was to achieve this, using substances without any potential addiction inducing capacity. The practical relevance and the prescription volume of such substances, Acamprosate [reaching not 1\% of the addicted patients (Fritze, 2003; Lohse et al., 2008) or not $5 \%$ of the appropriate patients (Fritze, 2007)], Naltrexone, and Disulfirame, remained similarly limited like Naltrexone for opiate addicts.

The failure of the addiction avoiding substances is a hint for the treatment. Addictive substances are used for tranquillization, to blank out bad things in the brain, sometimes to overcome displeasing self-consciousness, as patients say. The displeasing, inhibiting perceptions are sometimes described as a grave handicap, often hard, or impossible to bear. Craving is repeatedly stronger than willpower.

Many patients need an agonistic substance giving them some of the positive effects of alcohol. Alcohol itself is too toxic and connected with the described problems. Some substances, e.g., Benzodiazepines and Cannabinoides, seem not to be well 
applicable in the long term, because of their negative impact on the psychological resilience and of partly severe personality changes.

First encouraging results with Gamma-hydroxybutyrate (GHB), a GABA (B) receptor agonist, are mainly documented in Italian studies (Addolorato et al., 1996, 1998, 2000; Poldrugo and Addolorato, 1999; Maremmani et al., 2001; Caputo et al., 2003, 2005; Nava et al., 2006; Maremmani and Pacini, 2007). GHB is effective in reducing alcohol intake and in maintaining abstinence. Dangerous and fatal poisonings with GHB were reported, for instance from Spain (Galicia et al., 2008) and Sweden (Knudsen et al., 2008), and the substance is associated with a discussion about its abuse as k.o.drops or rape drug (Andresen et al., 2010; Németh et al., 2010). This seems to be a question of the right organization of the whole treatment.

Baclofen with a similar agonism, but different effect in practice, became popular because of a successful self-experiment of the physician Ameisen (2009). Once more Italians demonstrated that it can be effective treating severely alcohol dependent patients (Addolorato et al., 2002, 2007).

Clomethiazole is mainly prescribed as standard withdrawal medication (e.g., Hillemacher et al., 2008). Its use as agonistic substance for long term treatment, almost without therapeutic concept, was connected with life threatening emergency events, because of combined Alcohol-Clomethiazole poisonings. Official declarations defined Clomethiazole as obsolete for outpatient treatment (Deutsches Ärzteblatt, 1997).

Some alcohol dependents report good effects of amphetamines, concerning alcohol. A therapeutic use is not proven in this indication.

What about the Opioides? Heroin addicts frequently report that they stopped drinking, when they switched to heroin. A connection between alcohol and opiate receptors has been scientifically known for many years (Gianoulakis, 1993; Froehlich and Li, 1994; Gianoulakis and de Waele, 1994; Gianoulakis et al., 1996). The partial efficacy of opiate antagonists (Volpicelli et al., 1995) also demonstrates this connection. Caputo et al. (2002) again Italians, published possible effects of short-term methadone administration in reducing alcohol consumption in a population of non-alcoholic heroin-addicted patients. On the other side, many methadone maintenance patients have severe alcohol related problems. In individual cases raising the dosage of the opioid to very high dosages (methadone for instance to $400 \mathrm{mg}$ daily) was successful, giving us another hint that opioides can help to overcome alcohol addiction (Ulmer, 2010).

Two pioneering German doctors published first convincing experiences, treating alcohol dependent patients with DHC (Grimm, 1992; Elias, 1996). This idea was already published in 1929 (Kafemann, 1929), but then forgotten for decades. We started to carefully prescribe DHC in 1997, when one desperate patient, permanently suffering from craving and relapses, reported a strong reduction of his craving after the intake of analgetic tablets with each 30 mg Codeine TID (Ulmer, 2002; Ulmer et al., 2009).

\section{MATERIALS AND METHODS}

Meanwhile, we have treated 102 (M/F: 71/31) heavily alcohol addicted patients with DHC. In seven patients, who had problems with side effects of DHC or the necessary discipline (intake QID), we have alternatively tried Buprenorphine. Clomethiazole was evaluated as long term prescription, if we prescribed it for $>6$ weeks, in 40 patients. Our experience with Baclofen is initially based on seven patients, and in one patient, we have the best results, prescribing amphetamines. Our data is not the result of a study. No single prescription was study-motivated. Each patient signed an informed consent to be treated on a not established and therefore possibly dangerous way, including a very special responsibility. The treatment was always prescribed with the intention to provide the best possible treatment. But we always accompany our treatments with systematic documentation. This enables us to report what we observe.

\section{RESULTS}

The medical history alone of the 102 DHC-treated patients comprehended 1184 medically assisted detoxifications, 918 of them in a hospital, and 183 therapies in specialized clinics. Mean age of the patients was 46.6 years, mean duration of ostentatious alcohol consumption 23.2 years. The indication was an inability to live with or without alcohol in $87.3 \%$, in $27.5 \%$ urgent somatic, and in $13.7 \%$ urgent social reasons. Nineteen patients had a history of sporadic or dependent use of opiates, overcome for 9.2 years on average. The history of the patients treated with other substances than DHC is comparable. Clomethiazole was prescribed additionally to DHC, Buprenorphine, Methadone, or Baclofen in most cases. It was prescribed as single main drug for only 13 patients.

The patient whom we are treating with amphetamines, had a long stable history of $>30$ years with Fenetyllin prescribed by another physician, until it was suddenly withdrawn from the market. He tried to compensate with alcohol but 10 beers daily destroyed his life within only 3 years. Antidepressants, psychotherapy, and a treatment in a specialized hospital did not help. DHC from us was successful against alcohol, but not against a "black hole" in his soul. He has been much better treated with additional Amphetamin sulfate since $10 / 09$, the present dosage is $18 \mathrm{mg}$ /day (10.8 mg Amphetamine).

DHC normally has to be taken QID. Starting dosage in most cases was $120 \mathrm{mg}(4 \times 30 \mathrm{mg})$ daily. The mean dosage was raised up to $336 \mathrm{mg}$ after 57 months and then slowly reduced, to $137 \mathrm{mg}$ after 100 months (DHC-base). We have tended toward slightly higher dosages (Figure 1) in the last years. Of 72 patients, included until 08/07, 17 (23.6\%) remained on treatment 4 years later. Two had successfully finished the treatment without further relapses (4 years-retention rate together $26.4 \%$; Figure 2 ). This rate is $32.2 \%$, if all 13 , who finished the treatment within the first month, were excluded. Forty-eight percent of all patients remained in our treatment, after 4 years, even if DHC treatment was discontinued. In our 12-steps scale on clinical impression, we noticed a statistically significant improvement from mean 3.7 to 8.4 after 2 years $(n=29)$.

We have data about medically assisted detoxifications during the last 2 and the first 2 years on DHC from 19 of them: The number was reduced by $65.5 \%$ from 58 before to 20 during the first 2 years after DHC start (Figure 3). Mean GGT improved from 206.6 to $66.8 \mathrm{U} / \mathrm{l}$ after 2 years $(p=0.009$; Figure 4$)$. The MCV value also showed an improvement from $94.4 \mathrm{fl}$ at baseline to 92.9 fl after 2 years (Figure 5 ).

Mean GGT of patients with additional chronic hepatitis C $(n=12)$ improved from $260.8 \mathrm{U} / \mathrm{l}$ at baseline to $160.3 \mathrm{U} / \mathrm{l}$ after 


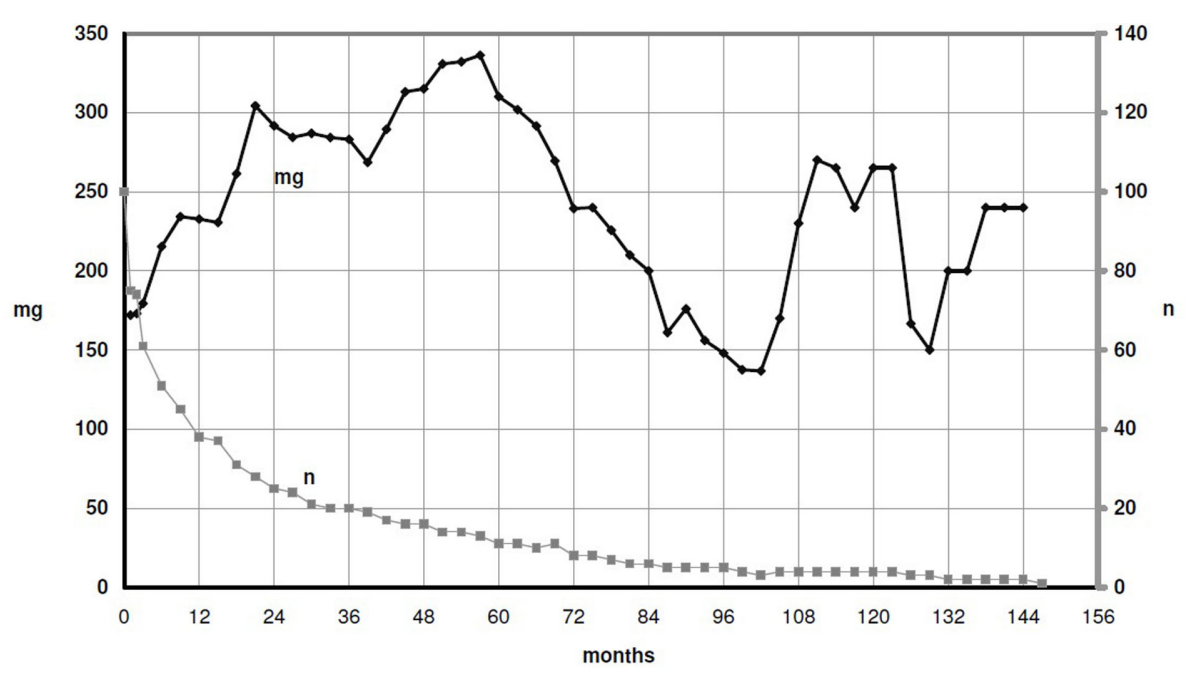

FIGURE 1 | Average daily dosage DHC. It was possible to control and to reduce the dosage over years. In some patients, the reduction was postponed in favor of the optimal dosage for a sustained stabilization, after a few years (peak of the dosage at the right).

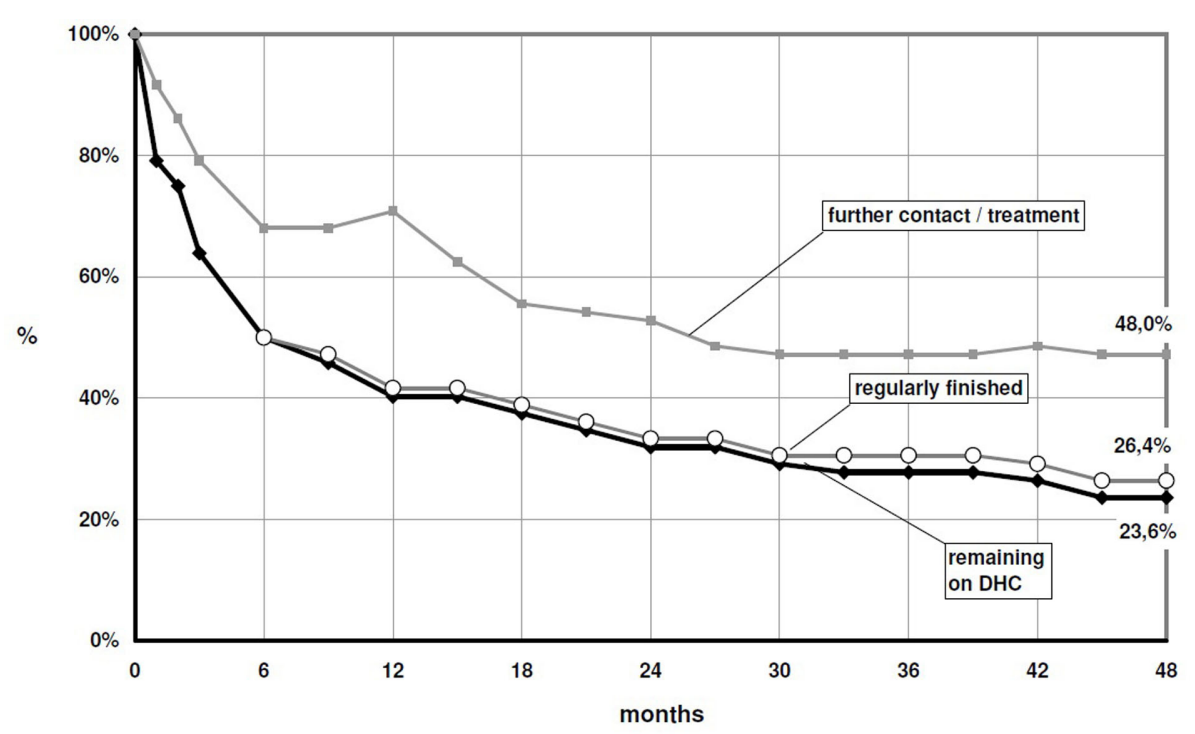

FIGURE 2 | Patients, remaining in our treatment, with or without DHC, including patients, who had regularly finished the DHC treatment without further relapse - insertion until 2007.

1 year $(p=0.139), 128.3$ after 2 years $(p=0.122)$, and 116.8 after 4 years ( $n$ here only 3 ).

Clomethiazole was prescribed more as an interim-medication and became a long term basic medication only in three patients. In most of the other cases, where it was prescribed alone, it was terminated early because of relapses, lost of follow up, or planned detoxification.

\section{DISCUSSION}

We do not present a designed study but the documentation of best possible practice. This means scientific limitations, no prospective design, external control, ethics committee, and no financial support for better statistics or evaluations. The scale of clinical impressions is not yet validated scientifically. On the other hand: We were not dependent on financial sponsors and could do much more than in studies, we could offer the best appraised treatment. It had the character of normal daily practice. Thus, we can address more practical aspects. These are as essential as the scientific aspects.

We are always aware that providing new, quasi experimental treatments can be dangerous for patients as well as for the doctor. Therefore, we permanently set high value on our integration in quality circles, interdisciplinary cooperation, and professional associations. We try to be especially accurate and to document as 


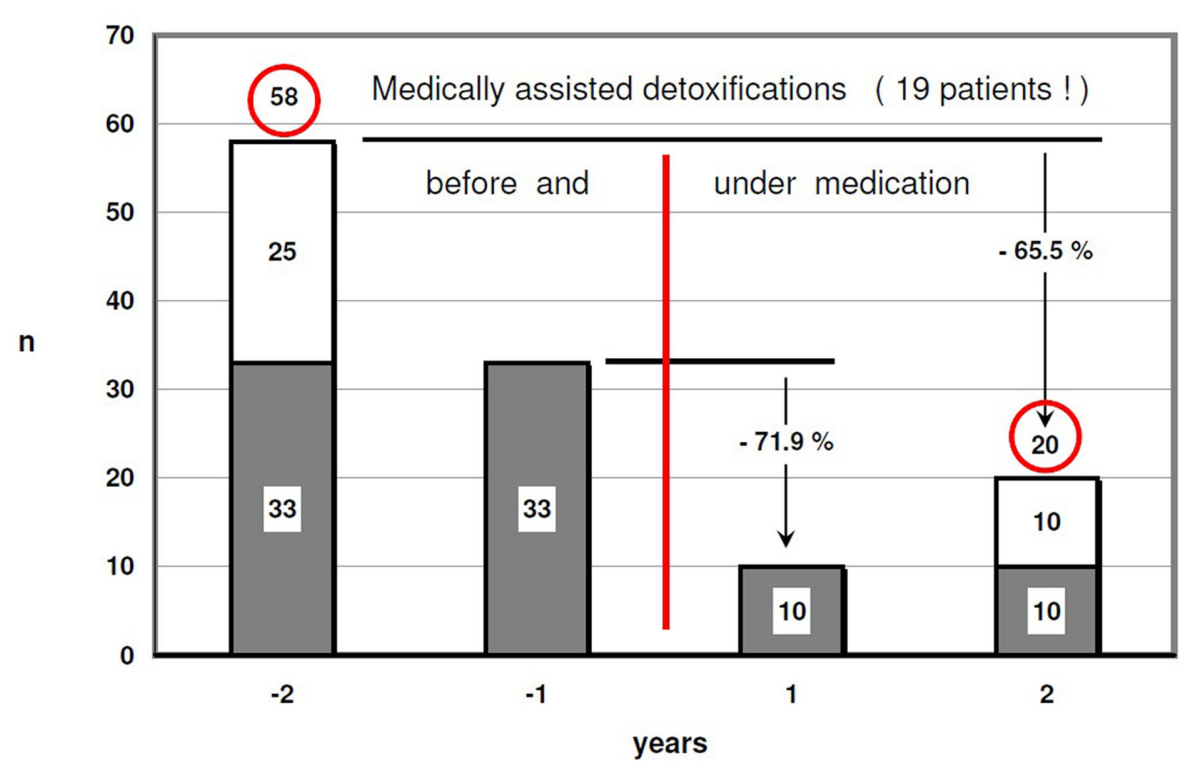

FIGURE 3 | Medically assisted detoxifications - patients with documented 2 years before and after start of the DHC treatment (58-20=-65.5\%!).

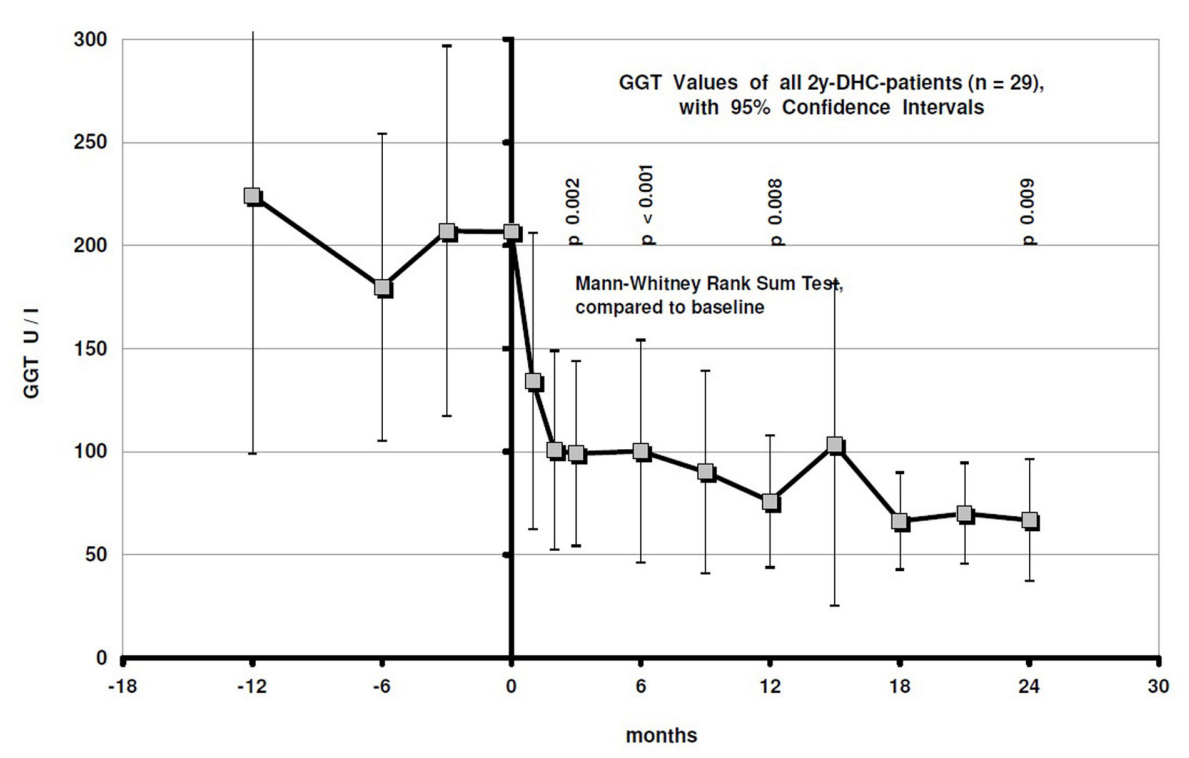

FIGURE 4 | GGT values with $95 \%$ confidence intervals during the last year before and the first 2 years on DHC treatment.

systematically as possible. This is generally a condition for better addiction medicine. We operate only on the basis of already existing knowledge and experience, never blindly experimenting. In most of our cases, not to leave the usual standard, would also have been dangerous, sometimes for the life of the patients. We always followed a reasonable probability to improve the situation with the new approach.

The immense number of previous detoxifications and therapies indicates the desperate state of many patients. Less than $10 \%$ of our charts, for $>20$ years, contain a documentation of a successful escape, with or without medication. Normally, it is a severe chronic disease with repeated exacerbations. Medical specialists and perspectives of a sufficient treatment are missing, when patients are discharged after countless detoxifications. Missing concepts induce permanently failing attempts to escape the addiction, expensive, dangerous, undermining their self-confidence. Result is again and again alcohol, the most adverse substance for a life with an addiction disease. The patients must live with this disease, but they have no adequate perspective, like with the most other chronic illnesses. To commit the patients as medical specialist is a very new perspective. Our 4 years-retention rate of together $48 \%$ in such desperate patients, $26.4 \%$ on DHC, indicates 


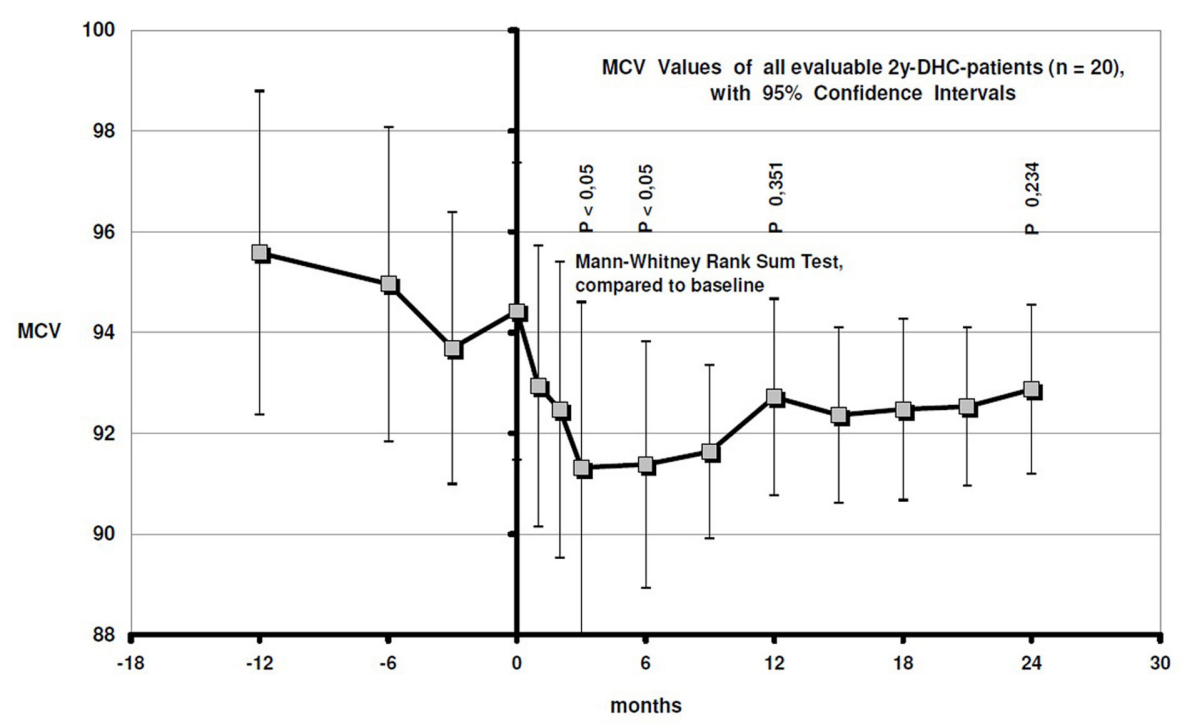

FIGURE 5 | MCV values with $95 \%$ confidence intervals during the last year before and the first 2 years on DHC treatment.

a new approach. We get closer to the treatment standard in other chronic diseases.

This is only possible with an effective basic medication. According to the nature of the disease and our experience, it must often be an agonistic substance or a combination of substances giving the patients at least a part of the alcohol effects. They are addicted, because they need something, like a patient with a thyroid hypofunction. The general - of course questionable - success of the maintenance therapies for opiate addicts, standard for a long ago, indicates the same. Concerning alcohol addiction, several studies are needed, to find out the best substances, combinations, and the best setting, generally and individually. The established maintenance treatment for opiate addicts suffers widely of some easily avoidable management failures and often also of questionable attitudes.

Therefore, not alone the use of agonistic substances has to be discussed but also the right management in combination with our attitudes. It is not sufficient only to provide with good substances like a provisioning of mass, even if an additional psychosocial care is organized.

The fear, to add a further and possibly more severe addiction to an existing addiction is coherent, but without reason. We enable a crucially better life with the addiction in the four essential parameters: somatic health, control, psychological stability, and underhandedness. In case of an insufficient effect and new relapses with alcohol, we can leave the treatment tapering the dosage, try another substance, possibly in combination, or continue, possibly increasing the dosage, because it appeared as the right way. All options are easily possible in most of such cases, of course connected with all psychological approaches.

In case of success, it is usually best to leave the patients on the medication for years, because, according to the chronic character of the disease, the risk of a change for the worse is higher the earlier we finish the treatment.
Prescribable agonistic substances are much better than alcohol. Almost no long term toxicity of opioides and the other substances is known. The experiences with the controllability are nearly perfect. If we advise them to take $30 \mathrm{mg}$ QID, they document an absolute correct use: $30 \mathrm{mg}$ QID. Also concerning the mental and intellectual capacity, our substances handicap and change the person less than alcohol. The situation of most patients has improved crucially.

Most of our prescribable substances are more dangerous, partly life threatening only in case of acute abuse and mixed intoxications. This is especially documented for GHB (Galicia et al., 2008; Knudsen et al., 2008), Clomethiazole (Deutsches Ärzteblatt, 1997), and DHC (Penning et al., 1993). The reaction of the experts as well as of the public authorities is always preferably too cautious. The good Italian experiences with GHB (Addolorato et al., 1996, 1998, 2000; Poldrugo and Addolorato, 1999; Maremmani et al., 2001; Caputo et al., 2003, 2005; Nava et al., 2006; Maremmani and Pacini, 2007) should have been internationally proven and integrated into therapy for a long time. But the substance is nearly not available in most countries.

Clomethiazole has lost its license for outpatient treatment in Germany and is not available in several countries. Most experts believe that its outpatient use is obsolete. The use of DHC for opiate addicts is, despite published good data (Ulmer, 1997; Krausz et al., 1998; Robertson et al., 2006), similarly restricted in Germany, and has been reduced from ca. 80 to $0.3 \%$ (Bundesinstitut für Arzneimittel und Medizinprodukte, 2011).

The professional world and public authorities are mistrusting. In doubt, they keep the doors of any potential development closed. But this is dramatic for the dependents. The observed tremendous difference between a normal treatment offer and the offer including exactly these medications remains withheld from them.

There will be no good development without bridging the gap between the two experiences: Dangerous abuse and a well 
controlled, very beneficial therapy on the other side. To win the confidence of the professional world and public authorities needs convincing solutions minimizing the danger of abuse as well as scientific results.

Putting the new treatment under cautious restrictions with a lot of control is the absolute wrong way. It undermines the trust between society and the physicians who provide this therapy, and also between the therapeutic team and the patient. Controls are necessary, of course, but if they get a central importance, connected with restrictions, we are on the old trip: taking care for the right way and mistrusting that the involved ones are aiming in the same direction. Restrictions, for instance demanding a special license for physicians and interfering in the choice and dosages of medical substances, are potentially as dangerous for the whole development as too much liberty. Permanently mistrusting controls, centralization in too few centers, questionable regulations and an attitude which always tries to first serve safety and only in second line patients and professionals, are often violating basics of good treatment and fundamental needs and rights of the patients, who have to take the basic medication for many years, sometimes lifelong. Long term patients need, more than others, trust as a central attribute of the treatment. It is absolutely essential to avoid or to overcome a second class identity. A good treatment construction must help the patients to have no further reason for underhandedness. This is only possible if restrictions are not the regular reaction to missing success or other problems.

The investigation of a therapy which possibly can be abused must essentially be connected with a comprehensive development of a setting which guarantees a high grade of confidence. The therapy needs to be controlled, but trustfully. Trust is only possible if all involved people are convinced that everyone is really aiming for the best. And trust is always mutual.

This is not difficult, but we need a new organization of the whole treatment:

- implementing as many physicians as possible, avoiding concentration of patients,

- ensuring quality assisting training, specialization, reflexion,

- supporting quality circles, interdisciplinary cooperation, support centers, and a regular evaluation of the satisfaction of all,

- defining standards like

o good anamnesis,

o normal checks,

o regular qualified talks,

o written information about the concept, the medication, the dosage,

\section{REFERENCES}

Addolorato, G., Caputo, F., Capristo, E., Domenicali, M., Bernardi, M., Janiri, L., Agabio, R., Colombo, G., Gessa, G. L., and Gasbarrini, G. (2002). Baclofen efficacy in reducing alcohol craving and intake: a preliminary doubleblind randomized controlled o clear advise, how to take the medication, and prescribing not much more than needed until the next appointment,

Intelligent management can prevent wrong usage and ensure a sufficient quality without exorbitant bureaucracy, constraining regulations, and dramatic disadvantages for the patients - an essential basis for the development of trust on all levels.

In the treatment of Alcohol addiction, our experience comprises different substances. Our way to the use of these substances is an example for an alternative medical advancement in practice: Following the hints of the patients, as in our first DHC- and Amphetamine-patients, trying all possible standard treatments, cooperating with as many other experts as possible, and connecting all these aspects with the experience as integrated specialized physicians. New approaches are then, very carefully and systematically, possible much earlier than controlled studies, which are sometimes never realized, sometimes many years later.

Our main experience is based on DHC, altogether our best substance, up to now. Many patients fear a medically induced opiate addiction, few have intolerable, but innocuous side effects like pruritus, nausea, or constipation, few have no positive effect and few do not like the mental effect, but if this all is not the case, the effect on the general feeling and the craving is often broadly ideal. In very few patients, we have tried Buprenorphine, in case of problems with DHC. The report of these few patients was: General feeling o.k., but less reduction of the Alcohol craving, possibly a question of the right dosage, which is limited in our setting, because of the costs. The effect of a constant low dosage Clomethiazole is mainly a slight sedation, much less influence on the general feeling as with DHC. The reports concerning the reduction of the craving are different. To avoid mixed intoxications with alcohol, the outpatient dosage must be strictly limited and patients need good instruction and supervision. Our experience with Baclofen is still too small for a relevant impression. The dosage in Italian trials was $30 \mathrm{mg}$ (Addolorato et al., 2007), and Italian colleagues say: The effect of Baclofen would be less impressive than of GHB. Our first impression was similar. With higher dosages, $>100 \mathrm{mg}$, the patients feel a clear reduction of strain and anxiety. The effect on the general feeling is not as comprehensive and the reduction of the alcohol craving seems less than under DHC. An advantage, similar to GHB, might be the less severe addiction, compared to opioides and Clomethiazole.

These are only preliminary impressions. Scientific comparisons and the evaluation of combinations should be part of official trials. The obvious effect of different substances out of different classes indicates hope on the development of a very individual medical offer in the future, like in other chronic diseases (e.g., depression). 
Addolorato, G., Leggio, L., Ferrulli, A., Cardone, S., Vonghia, L., Mirijello, A., Abenavoli, L., D’Angelo, C., Caputo, F., Zambon, A., Haber, P. S., and Gasbarrini, G. (2007). Effectiveness and safety of baclofen for maintenance of alcohol abstinence in alcohol-dependent patients with liver cirrhosis: randomised, doubleblind controlled study. Lancet 370, 1915-1922.

Ameisen, O. (2009). Das Ende meiner Sucht. Munic: Kunstmann-publishing.

Andresen, H., Sprys, N., Schmoldt, A., Mueller, A., and Iwersen-Bergmann, S. (2010). Gamma-hydroxybutyrate in urine and serum: additional data supporting current cut-off recommendations. Forensic Sci. Int. 200, 93-99.

Bundesinstitut für Arzneimittel und Medizinprodukte. (2011). Bericht zum Substitutionsregister. Available at: www.bfarm.de/ SharedDocs/1_Downloads/DE/ Bundesopiumstelle/BtM/substit-reg/ Subst_Bericht_2010.pdf?_blob = publicationFile, 3

Caputo, F., Addolorato, G., Domenicali, M., Mosti, A., Viaggi, M., Trevisani, F., Gasbarrini, G., Bernardi, M., and Stefanini, G. F. (2002). Short-term methadone administration reduces alcohol consumption in non-alcoholic heroin addicts. Alcohol Alcohol. 37, 164-168.

Caputo, F., Addolorato, G., Lorenzini, F., Domenicali, M., Greco, G., del RE, A., Gasbarrini, G., Stefanini, G. F., and Bernardi, M. (2003). Gammahydroxybutyric acid versus naltrexone in maintaining alcohol abstinence: an open randomized comparative study. Drug Alcohol Depend. 70, 85-91.

Caputo, F., Vignoli, T., Lorenzini, F., Ciuffoli, E., Del Re, A., Stefanini, G. F., Addolorato, G., Trevisani, F., and Bernardi, M. (2005). Suppression of craving for gamma-hydroxybutyric acid by naltrexone administration: three case reports. Clin. Neuropharmacol. 28, 87-89.

Deutsches Ärzteblatt. (1997). Warnende Hinweise zur Verschreibung von Clomethiazol (Distraneurin). Diskussionsbeiträge und Autorenschlußwort zum Beitrag von D. Färber und $R$. Tölle in 33/96. Cologne, Dt. Ärzteblatt 94/5 A-237-243.

Elias, H. (1996). “Medizinische Behandlung der Alkoholkrankheit im ambulanten Bereich," in Suchtmedizinischer Kongress der DGDS, Vol. 5, ed. J. Zerdick (Karlsruhe: Kongressband), 119-124.

Fritze, J. (2003). PsychopharmakaVerordnungen: Ergebnisse und Kommentare zum Arzneimittelverordnungsreport 2002 . Nervenarzt 74, 301-306.

Fritze, J. (2007). PsychopharmakaVerordnungen: Ergebnisse und Kommentare zum Arzneimittelverordnungsreport 2006 Nervenarzt 78, 1332-1338.

Froehlich, J. C., and Li, T. K. (1994). Opioid involvement in alcohol drinking. Ann. N. Y. Acad. Sci. 739, 156-167.

Galicia, M., Nogué, S., To-Figueras, J., Echarte, J. L., Iglesias, M. L., and Miró, O. (2008). Poisoning by liquid ecstasy (GHB) in hospital emergency departments of Barcelona: a 2-years study. Med. Clin. (Barc.) 130, 254-258.

Gianoulakis, C. (1993). Endogenous opioids and excessive alcohol consumption. J. Psychiatry Neurosci. 18, 148-156.

Gianoulakis, C., and de Waele, J. P. (1994). Genetics of alcoholism: role of the endogenous opioid system. Metab. Brain Dis. 9, 105-131.

Gianoulakis, C., de Waele, J. P., and Thavundayil, J. (1996). Implication of the endogenous opioid system in excessive ethanol consumption. Alcohol 13, 19-23.

Grimm, G. (1992). Drogen gegen Drogen. Kiel: Veris-Verlag.

Hillemacher, T., Weinland, C., Heberlein, A., Wilhelm, J., Bayerlein, K., Kornhuber, J., Frieling, H., and Bleich, S. (2008). Treatment with clomethiazole is associated with lower rates of premature discharge during alcohol withdrawal. Pharmacopsychiatry 41, 134-137.

Kafemann. (1929). Der Arzt, die Bekämpfung des Alkoholismus und die Alkoholgefährdeten. Med. Welt 8, 272-273.
Knudsen, K., Greter, J., and Verdicchio, M. (2008). High mortality rates among GHB abusers in Western Sweden. Clin. Toxicol. (Phila.) 46, 187-192.

Krausz, M., Verthein, U., Degkwitz, P., Haasen, C., and Raschke, P. (1998). Maintenance treatment of opiate addicts in Germany with medications containing codeine - results of a follow-up study. Addiction 93, 1161-1167.

Lohse, M. J., Lorenzen, A., MüllerOerlinghausen, B. M., in Schwabe, U., and Paffrath, D. (2008). Arzneiverordnungs-Report 2007. Berlin: Springer, 807.

Maremmani, I., Lamanna, F., and Tagliamonte, A. (2001). Longterm therapy using GHB (sodium gamma hydroxybutyrate) for treatment-resistant chronic alcoholics. J. Psychoactive Drugs 33 135-142.

Maremmani, I., and Pacini, M. (2007). Use of sodium gammahydroxybutyrate (GHB) in Alcoholic heroin addicts and polydrug-abusers. Heroin Addict. Relat. Clin. Probl. 9, 55-76.

Nava, F., Premi, S., Manzato, E., and Lucchini, A. (2006). Comparing treatments of alcoholism on craving and biochemical measures of alcohol consumptionst. J. Psychoactive Drugs 38, 211-217.

Németh, Z., Kun, B., and Demetrovics, $Z$. (2010). The involvement of gamma-hydroxybutyrate in reported sexual as-saults: a systematic review. J. Psychopharmacol. 24 1281-1287.

Penning, R., Fromm, E., Betz, P. Kauert, G., Drasch, G., and v. Meyer, L. (1993). Drogentodesfälle durch dihydrocodeinhaltige Ersatzmittel. Dtsch. Arztebl. 90, 528-525.

Poldrugo, F., and Addolorato, G. (1999). The role of gamma-hydroxybutyric acid in the treatment of alcoholism: from animal to clinical studies. Alcohol Alcohol. 34 15-24.

Robertson, J. R., Raab, G. M., Bruce, M., McKenzie, J. S., Storkey, H. R., and Salter, A. (2006). Adressing the efficacy of dihydrocodeine versus methadone as an alternative treatment for opiate dependence: a randomized controlled trial. Addiction 101, 1752-1759.

Ulmer, A. (1997). Die DihydrocodeinSubstitution. Darstellung der Behandlungsmethode anhand von Fragen des Bundessozialgerichtes und eines Entwurfes zur achten BetäubungsmittelrechtsÄnderungsverordnung. Stuttgart: Thieme-Verlag.

Ulmer, A. (2002). Substitutionsmöglichkeiten bei Alkoholabhängigen. Suchttherapie Suppl. 2, 127-128.

Ulmer, A. (2010). Starke Dosiserhöhung als erfolgreiche Antwort auf vorher unbeherrschbare Alkoholprobleme bei Methadonbehandlung. Suchttherapie 56, 283.

Ulmer, A., Müller, M., and Frietsch, B. (2009). Dihydrocodeine for the treatment of alcohol dependence. Heroin Addict. Relat. Clin. Probl. 11, 15-22.

Volpicelli, J. R., Clay, K. L., Watson, N. T., and O'Brien, C. P. (1995). Naltrexone in the treatment of alcoholism: predicting response to naltrexone. J. Clin. Psychiatry 56(Suppl. 7), 39-44.

Conflict of Interest Statement: The authors declare that the research was conducted in the absence of any commercial or financial relationships that could be construed as a potential conflict of interest.

Received: 18 January 2012; accepted: 28 February 2012; published online: 23 March 2012.

Citation: Ulmer A, Müller M and Frietsch B (2012) Dihydrocodeine/agonists for alcohol dependents. Front. Psychiatry 3:21. doi: 10.3389/fpsyt.2012.00021

This article was submitted to Frontiers in Addictive Disorders, a specialty of Frontiers in Psychiatry.

Copyright (c) 2012 Ulmer, Müller and Frietsch. This is an open-access article distributed under the terms of the Creative Commons Attribution Non Commercial License, which permits noncommercial use, distribution, and reproduction in other forums, provided the original authors and source are credited. 